\title{
CONTROLE GENÉTICO, QUÍMICO E BIOLÓGICO DE MELOIDOGINOSE NA CULTURA DA SOJA ${ }^{1}$
}

\author{
Fabio Fernando de Araujo², Rodrigo José Bragante ${ }^{2}$, Carlos Emanuel Bragante ${ }^{2}$
}

\section{ABSTRACT \\ GENETIC, CHEMICAL, AND BIOLOGICAL CONTROL OF ROOT-KNOT NEMATODES IN SOYBEAN CROP}

The control of nematodes with the use of different methods is important for success in the reduction of damage caused by these parasites. This study aimed to evaluate the effectiveness of methods for controlling root-knot nematodes in soybean. For that, the soybean BRS 282 genotype, resistant to Meloidogyne javanica and $M$. Incognita, was used for its genetic control, the nematicide carbofuran was used for its chemical control, and the Bacillus subtilis (PRBS-1 and B-1) was used for its biological control. Soybean BRS 282 (resistant) and BRS 184 (susceptible) seeds were treated or not with carbofuran and $B$. subtilis. The soil used in the experiment was collected in areas naturally infested with root-knot nematodes. In order to evaluate the control of root-knot nematodes, the plants were grown in a greenhouse, for 60 days. After this period, the active forms and nematodes eggs in the roots were quantified and plant growth evaluated. The use of the BRS 282 genotype was the best option for controlling root-knot nematodes in soybean, due to its low incidence in the roots. For the BRS 184 genotype, both the chemical and biological control were effective in reducing the nematode reproduction in soybean roots. The treatment of BRS 282 genotype seeds with carbofuran or $B$. subtilis significantly improved the soybean growth in soil infested with the parasite.

KEY-WORDS: Glycine max L.; Meloidogyne spp.; Bacillus subtilis; carbofuran.

\section{INTRODUÇÃO}

Dentre as doenças que limitam a produção de soja (Glycine max L.), no Brasil, as causadas por nematoides do gênero Meloidogyne estão entre as mais frequentemente associadas a danos na cultura, com ampla distribuição geográfica, sendo responsáveis por prejuízos crescentes (Almeida et al. 2005). Os nematoides deste gênero incitam galhas nas raízes e causam redução na absorção de nutrientes e transloca-

\section{RESUMO}

O controle de nematoides, com o uso de diferentes métodos, é importante para o sucesso na redução dos danos causados por estes parasitas. Objetivou-se, com este trabalho, avaliar a eficácia dos métodos de controle da meloidoginose da soja. Para isto, foi utilizado o genótipo de soja BRS 282, resistente a Meloidogyne javanica e M. incognita, no controle genético, o nematicida carbofurano no controle químico e o Bacillus subtilis (PRBS-1 e B-1) no controle biológico. Sementes de soja BRS 282 (resistente) e BRS 184 (susceptível) foram tratadas ou não com carbofurano e $B$. subtilis. O solo utilizado no experimento foi coletado em áreas naturalmente infestadas pelo nematoide das galhas. Para avaliação do controle da meloidoginose, as plantas foram cultivadas em casa-de-vegetação, durante 60 dias. Após este período, as formas ativas e ovos de nematoides nas raízes foram quantificados e o crescimento da planta avaliado. A utilização do genótipo BRS 282 foi a melhor opção para o controle da meloidoginose em soja, devido à sua baixa incidência nas raízes. No genótipo BRS 184, tanto o controle químico quanto o biológico foram eficazes na redução da reprodução do nematoide, em raízes de soja. O tratamento de sementes do genótipo BRS 282 com carbofurano ou B. subtilis contribuiu para ganhos significativos, no crescimento da soja cultivada em solo infestado pelo parasita.

PALAVRAS-CHAVE: Glycine max L.; Meloidogyne spp.; Bacillus subtilis; carbofurano.

mento de água, culminando com menor crescimento da parte aérea da planta (Tihohod 2000).

As meloidoginoses, quando favorecidas pelas condições edafoclimáticas, podem causar perdas consideráveis à produção, em diferentes culturas, tendo sido observado decréscimo de produtividade em soja da ordem de $30 \%$, em plantas infectadas por Meloidogyne javanica (Valiente et al. 1990).

O controle de nematoides deve ser planejado com a integração de vários métodos e apresentar

1. Trabalho recebido em fev./2012 e aceito para publicação em jun./2012 ( $\mathrm{n}^{\circ}$ registro: PAT 17183).

2. Universidade do Oeste Paulista, Faculdade de Ciências Agrárias, Presidente Prudente, SP, Brasil.E-mails: fabio@unoeste.br, rodrigo.bragante@belagricola.com.br, faruaj@yahoo.com.br. 
baixo custo, sendo recomendados, com frequência, a rotação de culturas, o uso de genótipos resistentes e o controle químico e biológico (Almeida et al. 2005).

O desenvolvimento e uso de genótipos com resistência genética é um método efetivo de se limitar perdas de rendimento de soja causadas por Meloidogyne spp. (Pedrosa et al. 1994). Entretanto, a maioria dos genótipos de soja cultivados no Brasil tem apresentado histórico de susceptibilidade a Meloidogyne javanica e M. incognita (Roese et al. 2004).

O controle químico de meloidoginose em soja, com o uso de carbofurano, já foi considerado eficiente método no controle de $M$. javanica (Novaretti et al. 1982). Contudo, os nematicidas químicos têm seu uso cada vez mais restrito, por sua alta toxicidade e baixa eficácia de controle, após repetidas aplicações (Dong \& Zhang 2006).

Já foi destacado que o controle biológico proporcionado por rizobactérias no solo pode ser utilizado no manejo destes parasitas, já que muitos micro-organismos deste grupo são capazes de promover proteção substancial contra os nematoides (Tian \& Riggs 2000). Neste sentido, isolados selecionados de Bacillus subtilis foram relatados como antagonistas a Meloidogyne spp., podendo ser utilizados em programas de controle de nematoides em culturas econômicas (Araujo \& Marchesi 2009). Dentro deste cenário, decidiu-se avaliar o desenvolvimento de Meloidogyne spp. em dois genótipos de soja resistentes e susceptíveis a meloidoginoses associadas ao tratamento de sementes com nematicida químico e Bacillus subtilis, objetivando definir a eficácia dos diferentes métodos de controle empregados.

\section{MATERIAL E MÉTODOS}

O experimento foi conduzido em casa-de-vegetação, durante o ano de 2010, utilizando-se vasos com $3 \mathrm{~kg}$ de solo (Latossolo Roxo), coletado em área tradicional de cultivo de soja em Alvorada do Sul (PR), com histórico de alta infestação de nematoide de galhas. Pela análise de extração de nematoides do solo, segundo metodologia de Jenkies (1964), foi detectada a presença de 3.400 formas ativas de Meloidogyne spp., em $100 \mathrm{~cm}^{3}$ de solo.

Foram utilizados os genótipos de soja BRS 184 e BRS 282, sendo que o BRS 282 é caracterizado como resistente às principais espécies de nematoides de galha, como Meloidogyne incognita e Meloidogyne javanica (Embrapa 2008).

Os dois genótipos foram submetidos a tratamentos de sementes com nematicida carbofurano (Furadan 350TS ${ }^{\circledR}$ ), na dose de 175 g $50 \mathrm{~kg}$ de sementes $^{-1}$, e inoculação de dois isolados de Bacillus subtilis (PRBS-1 e B-1), na dose de $500 \mathrm{~g} 50 \mathrm{~kg}$ de sementes $^{-1}$. O delineamento experimental empregado foi o de blocos inteiramente casualizados, com distribuição em arranjo fatorial $2 \times 4$, sendo dois genótipos e quatro tratamentos de sementes e quatro repetições. Cada vaso representava uma parcela e, no total, foram constituídas 32 parcelas.

Os isolados de $B$. subtilis foram multiplicados durante sete dias, em $100 \mathrm{~mL}$ de caldo nutriente ( $3 \mathrm{~g} \mathrm{~L}^{-1}$ de extrato de levedura e $5 \mathrm{~g} \mathrm{~L}^{-1}$ de peptona). Decorrido este período, o meio de cultura foi centrifugado e o precipitado contendo as células misturado com $100 \mathrm{~g}$ de bentonita. Esta mistura foi homogeneizada e seca por 48 horas, em estufa com ventilação forçada $\left(40^{\circ} \mathrm{C}\right)$. $\mathrm{O}$ produto final seco apresentou a concentração de $B$. subtilis de $1,0 \times 10^{9}$ células $\mathrm{g}^{-1}$, avaliada pelo método de diluição seriada em placas. Esta quantificação foi determinada pela diluição inicial de $1,0 \mathrm{~g}$ do produto em solução salina estéril acondicionada em tubo de ensaio e, a partir deste primeiro tubo, foram realizadas diluições sucessivas, finalizando-se com a retirada de alíquota $(0,1 \mathrm{~mL})$ do último tubo e plaqueamento em meio de cultura sólido (ágar nutriente). A inoculação consistiu em misturar as sementes com os produtos, após o umedecimento das mesmas com solução adesiva à base de água e açúcar (100 $\mathrm{g} \mathrm{L}^{-1}$ de glicose), na proporção de $1,0 \mathrm{~mL} \mathrm{~kg} \mathrm{de}$ sementes $^{-1}$. Imediatamente após o tratamento das sementes, foi efetivada a semeadura no solo.

As plantas foram cultivadas durante 60 dias, em casa-de-vegetação, com reposição periódica da umidade do solo, para atingir a capacidade de campo. Após este período, as plantas foram coletadas cuidadosamente, separando-se a parte aérea das raízes, sendo que a parte aérea foi seca em estufa $\left(60^{\circ} \mathrm{C}\right)$, até atingir peso constante, e, posteriormente, pesada, enquanto as raízes frescas foram pesadas e submetidas a procedimentos de extração de nematoides, utilizando-se o método de Coolen \& D’Herde (1972). Após a contagem de ovos e formas ativas de Meloidogyne spp., os resultados foram expressos em ovos e formas ativas por grama de raiz. Os dados obtidos foram submetidos a análise de variância e teste $\mathrm{F}$, utilizando-se o teste Scott-Knott (5\%), para comparação das médias. 


\section{RESULTADOS E DISCUSSÃO}

O tratamento de sementes de soja com $B$. subtilis ou carbofurano não incrementou o controle dos nematoides avaliado pela contagem de ovos e formas ativas nas raízes, no genótipo de soja BRS 282, resistente ao parasita (Tabelas 1 e 2). Por outro lado, ocorreu redução significativa de, aproximadamente, $70 \%$ na presença de formas ativas e ovos, nas raízes do genótipo de soja BRS 184, susceptível ao parasita, quando as sementes foram tratadas com $B$. subtilis (B-1). O isolado PRBS-1 de B. subtilis e o carbofurano proporcionaram reduções inferiores no número de formas ativas e ovos, respectivamente, apesar de significativamente diferentes do controle, indicando, neste caso, que o controle biológico foi tão eficiente quanto o controle químico, na redução de formas ativas e ovos de Meloidogyne spp. em soja.

Nunes et al. (2010), em estudo com o uso de agentes microbianos e químicos, para controle da

Tabela 1. Número de formas ativas de Meloidogyne spp. em raízes de dois genótipos de soja (BRS 184 e BRS 282), em função do tratamento com carbofurano e Bacillus subtilis (Alvorada do Sul, PR, 2010).

\begin{tabular}{|c|c|c|c|}
\hline \multirow{3}{*}{ Tratamento } & \multicolumn{2}{|c|}{ Cultivares } & \multirow{2}{*}{ Médias } \\
\hline & BRS 184 & BRS 282 & \\
\hline & \multicolumn{3}{|c|}{$\mathrm{n}^{\circ}$ de formas ativas $\mathrm{g}$ de raiz $^{-1}$} \\
\hline Controle & $5.300 \mathrm{aA}$ & $215 \mathrm{aB}$ & $2.757 \mathrm{a}$ \\
\hline Carbofurano & $1.602 \mathrm{bA}$ & $226 \mathrm{aB}$ & $948 \mathrm{~b}$ \\
\hline B. subtilis (B-1) & $1.464 \mathrm{bA}$ & $294 \mathrm{aB}$ & $845 \mathrm{~b}$ \\
\hline B. subtilis (PRBS-1) & $2.265 \mathrm{bA}$ & $296 \mathrm{aB}$ & $1.280 \mathrm{ab}$ \\
\hline Médias & $2.658 \mathrm{~A}$ & $258 \mathrm{~B}$ & 1.458 \\
\hline
\end{tabular}

Médias seguidas da mesma letra minúscula, na coluna, e maiúscula, na linha, não diferem entre si, pelo teste Scott-Knott, a 5\%.

Tabela 2. Número de ovos de Meloidogyne spp. em raízes de dois genótipos de soja (BRS 184 e BRS 282), em função do tratamento de sementes com carbofurano e Bacillus subtilis (Alvorada do Sul, PR, 2010).

\begin{tabular}{|c|c|c|c|}
\hline \multirow{3}{*}{ Tratamento } & \multicolumn{2}{|c|}{ Cultivares } & \multirow{2}{*}{ Médias } \\
\hline & BRS 184 & BRS 282 & \\
\hline & \multicolumn{3}{|c|}{$\mathrm{n}^{\circ}$ de ovos g de raiz $^{-1}$} \\
\hline Controle & $15.444 \mathrm{Aa}$ & $1.086 \mathrm{aB}$ & $8.265 \mathrm{a}$ \\
\hline Carbofurano & $7.171 \mathrm{bA}$ & $1.553 \mathrm{aB}$ & $4.362 \mathrm{~b}$ \\
\hline B. subtilis (B-1) & $4.211 \mathrm{bA}$ & $1.155 \mathrm{aB}$ & $2.683 \mathrm{~b}$ \\
\hline B. subtilis (PRBS-1) & $4.717 \mathrm{bB}$ & $1.409 \mathrm{aB}$ & $3.063 \mathrm{~b}$ \\
\hline Médias & $7.885 \mathrm{~A}$ & $1.301 \mathrm{~B}$ & 4.593 \\
\hline
\end{tabular}

meloidoginose em soja, concluíram que apenas o controle químico proporcionou o controle de formas ativas e ovos do parasita. Em outro estudo de avaliação do controle biológico do nematoide com B. subtilis, foi encontrada redução significativa apenas de ovos e número de galhas nas raízes (Burkett-Cadena et al. 2008).

Apenas o emprego do genótipo resistente não resultou em acréscimo significativo, na produção de massa seca na parte aérea das plantas, quando comparado ao genótipo susceptível (Figura 1). Os controles químicos e biológicos também não proporcionaram ganhos significativos no crescimento da parte aérea do genótipo susceptível ao nematoide. Entretanto, o uso da resistência genética, aliado aos tratamentos biológico e químico, proporcionou incrementos significativos no crescimento da planta, avaliados pelo teste $F(p<0,05)$. Não foi detectada fitotoxidez associada aos tratamentos.

Kamunya et al. (2008) relataram que o uso de genótipos resistentes é, indiscutivelmente, a melhor opção, apresentando-se como ambientalmente correta e de baixo custo, para controlar nematoides. Contudo, o uso de outras técnicas associadas pode proporcionar melhores resultados.

Herman et al. (1991), analisando a penetração e desenvolvimento de Meloidogyne incognita, em raízes de genótipos de soja resistentes, observaram que, com o passar dos dias, a população do parasita aumentou na rizosfera das plantas resistentes, fato,

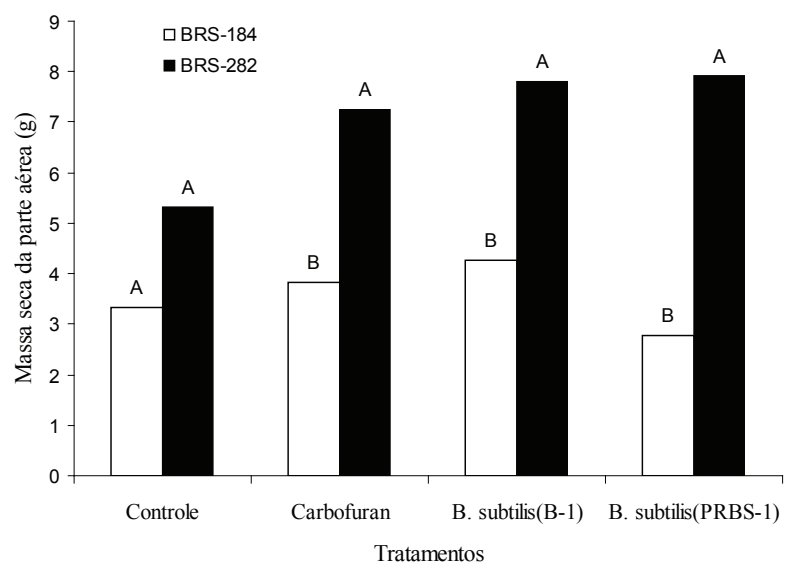

Figura 1. Massa seca da parte aérea de dois genótipos de soja (BRS 184 e 282), em função do tratamento de sementes com carbofurano e Bacillus subtilis (B-1 e PRBS-1) (Alvorada do Sul, PR, 2010). Letras, nas colunas, comparam os genótipos, dentro do mesmo tratamento, utilizando-se o teste Scott-Knott, a 5\%. 
este, chamado de emigração de nematoides, no qual o parasita consegue penetrar, mas causa lesões em diferentes locais, nas raízes. Este fato pode sugerir que a ocorrência de danos superficiais nas raízes afeta, de algum modo, o crescimento da planta. Além disto, existe, também, o risco de o cultivo contínuo de um genótipo resistente selecionar alguns biótipos virulentos de Meloidogyne spp. (Pedrosa \& Moura 2001).

A inoculação de Bacillus subtilis, além de reduzir a severidade da doença, também influencia positivamente no crescimento das plantas (Burkett-Cadena et al. 2008). Este efeito já foi comprovado em estudo de avaliação do controle de meloidoginose em cana-de-açucar, onde $B$. subtilis controlou efetivamente o parasita e também promoveu o crescimento da planta (Cardozo \& Araujo 2011). Esta constatação também foi relatada em outro estudo, com o Bacillus subtilis reduzindo a reprodução de Meloidogyne spp. em raiz de tomate, confirmando o seu potencial para uso em programas de manejo integrado da meloidoginose em tomateiro (Araujo \& Marchesi 2009). O efeito de B. subtilis no aumento do crescimento da soja já foi estudado, encontrando-se, como principais modos de ação, a influência de fitoreguladores e antibióticos, no crescimento e sanidade da cultura, respectivamente (Araujo et al. 2005).

Genótipos resistentes, como o BRS 282, podem ser indicados como eficazes no controle da meloidoginose em soja. Entretanto, já foi constatado que alguns genótipos de soja resistentes a meloidoginoses não apresentavam boa estabilidade produtiva (Silva 2001). O genótipo BRS 282 apresenta maior estabilidade produtiva e ampla adaptação às regiões de cultivo de soja no Brasil (Embrapa 2008), porém, foi observado que o seu desempenho de crescimento (Figura 1) pode ser otimizado com a aplicação de métodos associados, para o controle dos nematoides no solo.

Os controles biológico e químico, avaliados neste trabalho, podem ser utilizados como estratégia no manejo desses parasitas, podendo ser recomendados mesmo em cultivos de soja resistente a meloidoginoses. A adoção desta prática irá diminuir a pressão dos nematoides na quebra da resistência e também reduzirá a amplitude do impacto ambiental, pois os tratamentos serão efetuados na semente. Resultados semelhantes também foram encontrados por Higaki (2012), quando associaram o controle químico e biológico ao uso de genótipo de algodoeiro resistente a nematoides. Entretanto, outros estudos envolvendo a aplicação do controle biológico de meloidoginoses com $B$. subtilis, em condições de campo, são necessários.

\section{CONCLUSÕES}

1. O método de controle genético utilizando o genótipo de soja BRS 282 foi o mais eficaz no controle da meloidoginose, embora a associação com o tratamento químico ou biológico de sementes tenha contribuído para o crescimento das plantas.

2. O controle químico com o uso do carbofurano e biológico com Bacillus subtilis, via tratamento de sementes, foram eficazes na redução do desenvolvimento do nematoide, no genótipo susceptível.

\section{REFERÊNCIAS}

ALMEIDA, A. M. R. et al. Doenças da soja. In: KIMATI, H. et al. Manual de fitopatologia. São Paulo: Agronômica Ceres, 2005. p. 569-588.

ARAUJO, F. F.; HENNING, A. A.; HUNGRIA, M. Phytohormones and antibiotics produced by Bacillus subtilis and their effects on seed pathogenic fungi and on soybean root development. World Journal of Microbiology and Biotechnology, Dordrecht, v. 21, n. 8-9, p. 1639-1645, 2005.

ARAUJO, F. F.; MARCHESI, G. V. P. Uso de Bacillus subtilis no controle da meloidoginose e na promoção do crescimento do tomateiro. Ciência Rural, Santa Maria, v. 39, n. 5, p. 1558-1561, 2009.

BURKETT-CADENA, M. et al. Suppressiveness of rootknot nematodes mediated by rhizobacteria. Biological Control, Palo Alto, v. 47, n. 1, p. 55-59, 2008.

CARDOZO, R. B.; ARAUJO, F. F. Multiplicação de Bacillus subtilis em vinhaça e viabilidade no controle da meloidoginose, em cana-de-açúcar. Revista Brasileira de Engenharia Agrícola e Ambiental, Campina Grande, v. 15, n. 6, p. 1283-1288, 2011.

COOLEN, W. A.; D'HERDE, C. J. A method for the quantitative extraction of nematodes from plant tissue. Ghent: State Agricultural Research Centre, 1972.

DONG, L. Q.; ZHANG, K. Q. Microbial control of plantparasitic nematodes: a five-party interaction. Plant Soil, The Hague, v. 288, n. 1-2, p. 31-45, 2006.

EMPRESA BRASILEIRA DE PESQUISA AGROPECUÁRIA (Embrapa). Nova cultivar de soja resistente aos nematoides de galha. 2008. Disponível 
em: <www.embrapa.br/imprensa/noticias/2008/janeiro/>. Acesso em: 20 dez. 2008.

HERMAN, M.; HUSSEY, R. S.; BOERMA, H. R. Penetration and development of $M$. incognita on roots of resistant soybean genotypes. Journal of Nematology, Hanover, v. 23, n. 1, p. 155-161, 1991.

HIGAKI, W. A. Bacillus subtilis e abamectina no controle de Rotylenchulus reniformis e Pratylenchus brachyurus e alterações fisiológicas em algodoeiro em condições controladas. 2012. 59 f. Dissertação (Mestrado em Agronomia)-Universidade do Oeste Paulista, Presidente Prudente, 2012.

JENKIES, W. R. A rapid centrifugal-flotation technique for separating nematodes from soil. Plant Disease Reporter, Saint Paul, v. 48, n. 5, p. 692-693, 1964.

KAMUNYA, S. M. et al. Integrated management of root-knot nematode (Meloidogyne spp.) in tea (Camellia sinensis) in Kenya. International Journal of Pest Management, London, v. 54, n. 1, p. 129-136, 2008.

NOVARETTI, W. R. T.; MIRANDA, M. A. C.; ALCÂNTARA, V. S. B. Tratamento químico visando o controle de nematoides em soja. Nematologia Brasileira, Piracicaba, v. 5, n. 2, p. 247-255, 1982.

NUNES, H. T. et al. Uso de agentes microbianos e químico para o controle de Meloidogyne incognita em soja. Acta Scientiarum Agronomy, Maringá, v. 32, n. 3, p. 403-409, 2010.
PEDROSA, E. M. R.; HUSSEY, R. S.; BOERMA, H. R. Response of resistant soybean plant introductions to Meloidogyne arenaria races 1 and 2. Journal of Nematology, Hanover, v. 26, n. 1, p. 182-187, 1994.

PEDROSA, E. M. R.; MOURA, R. M. Effect of continuous growing of resistant soybean genotypes on Meloidogyne arenaria race 1 reproduction. Fitopatologia Brasileira, Brasília, DF, v. 26, n. 1, p. 93-94, 2001.

ROESE, A. D. et al. Reação de cultivares de soja (Glycine max L. Merril) a Meloidogyne paranaensis. Nematologia Brasileira, Piracicaba, v. 28, n. 1, p. 131-135, 2004.

SILVA, J. F. V. Resistência genética de soja a nematoides do gênero Meloidogyne. In: SILVA, J. F. V. (Ed.). Relações parasito-hospedeiro nas meloidoginoses da soja. Londrina: Embrapa Soja/Sociedade Brasileira de Nematologia, 2001. p. 95-127.

TIHOHOD, D. Nematologia agrícola aplicada. 2. ed. Jaboticabal: Funep, 2000.

TIAN, H. L.; RIGGS, R. D. Effects of rhizobacteria on soybean cyst nematode, Heterodera glycines. Journal of Nematology, Hanover, v. 32, n. 2, p. 377-388, 2000.

VALIENTE, A. R. et al. Assessment of yield losses due to root-knot nematode species in soybean. International Nematology Network Newsletter, Raleigh, v. 7, n. 1, p. 42-43, 1990. 